\title{
The evolution of harmony in the music of the Democratic Republicof Congo (DRC)
}

Abstract: This article reveals the concept of music encapsulated in the $18^{\text {th }}$ century Enlightenment definition of music that failed to recognize the existence of expressions outside Europe. In 1964, the American anthropologist Alan Merriam (1923-1980), provided a broad-based definition of music according to the substance of Franz Boas' theory of "Cultural Relativism", which empowers individual communities to define music within the frame of reference of their owncultural context. In the present article, I argue that there are three types of harmony in the music of the Democratic Republic of Congo reflected in: 1) The linear harmony encapsulated in Ensemble Thematic Cycle (ETC) of traditional music interpreted by drum ensembles, 2) The homophonic harmony of Western genre implemented in chord progressions by urban bands composed of a variety of musical instruments, 3) The parallel harmony of vocal singing as linguisticallyimposed to maintain the communicative significance of the message in lyrics.

The Oxford Dictionary of Music (2010) defines harmony as the combination of notes simultaneous sounded in a vertical (chord) relation. The definition is certainly basedon the European perception of harmony, seen as being consonance and/or dissonance. Whereas the former is considered by many to be a pleasant and agreeable to the ears, the latter is not so pleasant or soothing. This Eurocentric concept of harmonic practice has been indiscriminately imposed on cultures around the world, ignoring that this aspectof music is 
culturally specific.' What is neglected to be considered by those who share Eurocentric views of harmony is that, although the universals of music such as pitch, harmony, rhythm, are shared by all cultures, the configuration of their relationship in a composition is unique to each culture. Hence, all harmonic implications are not the same,i.e., what is received as pleasing in one culture may not be perceived in the same light inanother. Put differently, it is safe to assert that music is best understood in the context ofthe culture where it was created. European harmony is not based on the same principlesas the Chinese, the Mongolian, or for that matter, the African harmonies. Each of these is built on a set of esthetic values and norms different from the other. This chapter is devoted to the analysis of harmonic evolution in the popular music of DRC from the instrumental and vocal perspectives.

Debating the development of harmony in Europe, which evolved out of constant struggle for supremacy between music and the written literature, unaware writers erroneously concluded that the prevalence of parallel harmony in the vocal singing in Africa is evidence of African musicians' inability to develop their harmony. There are thosewriters who even believe that parallel singing is the only style of harmonic texture familiarto African musicians. This misconception stems from the instruction, or lack thereof, disseminated by the colonial administrators and missionaries, in classrooms or church settings, and, in chronicles and diaries left behind by early travelers. For the most part, these instructors and the supporting documents are sustained by the European concept of music without due consideration to the existence of a variety of musical traditions outside Europe. For example, these documents stressed the knowledge about the technique of sound production on respective European musical instruments within the European concept of diatonic harmony. For a very long period, the latter harmonic practice became known and adopted as the basis in musical training for majority of youngAfrican musicians.

\section{Ensemble Thematic Cycle (ETC)}

In his 1954 article, "Notes sur la Musique d'Afrique Centrale", Paul Collaercompares the development of harmony in Europe with that in Africa 
KAZADI WA MUKUNA The evolution of harmony in the music of the Democratic Republic of Congo (DRC)

and emphasizes thatboth traditions developed harmony simultaneously, but he continues, in Africa, thedevelopment of harmony stopped at the stage equivalent to that of $13^{\text {th }}$ century in Europe.

Collaer writes, “. . . and the black polyphony followed similar evolutionary phases as thatof the European. But blacks [Africans] stopped the development of their harmony at the $13^{\text {th }}$ century phase of European harmony." In this article, Paul Collaer ignored the teaching of the 1887 theory of "cultural relativism' in which the German-born Americananthropologist Franz Boas (1858-1942) asserted that a person's beliefs and practices should be understood based on that person's own culture. In other terms, cultural relativism warns scholars against judging a culture to their own standards of what isright or wrong, strange, or normal. Instead, these beliefs and practices should be understood in their own cultural context. ${ }^{3}$

In his assessment of the development of harmony, Collaer failed to comprehend the role of language in these two cultures-African and European. The concept of harmony is not built on similar set of principles derived from respective languages. For example, whereas in the non-tonal languages of Europe, composers could sacrifice the clarity of the text with the setting to the same madrigal lyrics in three different languages(French, Latin, and Italian). ${ }^{4}$ With the tonal languages of Africa, the melodic contour is dictated by the sequential pattern of tones on each word, which also determines the meaning of the word. In short, Meki Nzewi writes, "African musical intellection is guidedby principles and standards of form and structure." ${ }_{5}$

Often, the above error is committed by scholars who fail to approach this subject within an African frame of reference. In the instrumental performance, the harmonic texture is expressed in a linear layout derived from the intertwined relationship of time- line patterns rendered on differently pitched

\footnotetext{
${ }^{2}$ Paul Collaer. "Notes sur la Musique d'Afrique Centrale." Problèmes d'Afrique Centrale 26 (1954), p. 269.

3 https://search.yahoo.com/yhs/search?hspart = trp\&hsimp=yhs-001\&grd = 1\&type =Y61 F1_148993_042821\&p=cultural+relativism + definition\&rdr=1 - Accessed September 17, 2021.

4 The $16^{\text {th }}$-century Ecumenical Council of the Catholic Church that convened in Trento (then capital of the Prince Bishopric of Trent, inside the Holy Roman Empire, between December 13, 1545, and December 4, 1563, in twenty-five sessions for three periods to discuss various issues of great concern to the Church.
}

5 Meki Nzewi. African Music: Theoretical Content and Creative Continuum - The Culture Exponent's Definitions. Olderhausen, Germany: Institut für Didaktik Populärer Musik, 1997, p. 31 
percussive instruments. The resulting rhythmic tapestry comes out of the relationship created by the combination of time-line patterns played in an interlocking (hocket) fashion. The technique is where the constituent notes or rhythmic pattern are played at an exact point on particular instruments."' In otherwords, "Each pattern contains holes that provide receptacles for other patterns . . . although it may be perceived as a temporal part of the composition, the relationship between the patterns is by implication also perceived as a melodic formula." Meki Nzewirefers to this procedural concept as the melorhythm:

The significant musical form or module by which a piece of African music is recognized. Its length and significant content are the lowest commonmultiple of the unequal lengths cum differentiated contents of all the compositional themes assigned the various instruments of an ensemble forthe purposes of the performance-composition of a piece on anyperformance occasion or session. ${ }^{8}$

In other words, according to Meki, the melorhythm is the actual melody (ETC) that resultsfrom the interwoven relationship between time-line patterns of different lengths performedon differently pitched instruments in an ensemble. Elsewhere I assert that although an Ensemble Thematic Cycle (ETC) is conceptualized rhythmically, the evolutionary process of its fulfillment engenders the melodic and harmonic dimensions of the performance- composition. ${ }^{9}$ I assert that the linear harmony is the default harmonic texture in drum ensemble music. This mode of thinking about the harmonic implication in African drum ensemble music, has evaded the understanding of non-African students of African musicand that of casual African writers alike.

\section{INSTRUMENTAL HARMONY}

6 Kwabena J. H. Nketia. "The Hocket-Technique in African Music." Journal of the International Folk MusicCouncil 14 (1962), p. 44.

7 Kazadi wa Mukuna. "Creative Practice in African Music." Black Music Research Journal 17, 2 (Fall 1997), p. 242.

8 Meki Nzewi, op. cit., p. 44.

$9 \quad$ Kazadi wa Mukuna, op. cit., p. 243. 
KAZADI WA MUKUNA The evolution of harmony in the music of the Democratic Republic of Congo (DRC)

In the popular music of the DRC, the instrumental harmonic texture followsorganizational principles as those of the ETC detailed above, but with a different result. Whereas the relationship between time-line-patterns in a drum ensemble result in a linear harmony encapsulated in "melorhythm", the combination of shortmelodic phrases performed by different imported musical instruments (guitar, saxophone, double-bass, and others) in the popular bands, provides a tapestry ofharmonic progression that embellishes the vocal melodic contour, ${ }^{10}$ on which melodic formula are improvised by the lead guitar player. Bob White writes, "This layering together with the already layered multiple guitars parts, gives a thick, lushsound to the music, which is often described by non-native listeners as "rich" or "full"." In summation, the organizational concept of the Ensemble Thematic Cycle(E.T.C.) is primarily the symbiotic relationship between rhythmic patterns, the resulting harmony is just its byproduct. Contrary to the melorhythm, the contribution of each instrumental part in the popular ensemble fulfils the role of both rhythmic and harmonic ornamentation for the guitar solo and/or the vocal melody, to enrich the texture of the music.

During the so-called "Troubadour" period (1939-ca. 1960s), when the style of popular music of DRC was being defined, expatriate owners of recording studios donateda variety of Western instruments (guitars, saxophones, clarinets, and flutes) to talented Congolese music amateurs, and hired professional European players to introduce Congolese musicians to techniques of sound production on their respective instruments and, with it, they also introduced the European diatonic chord progression of tonic- subdominant-dominant-tonic (I-IV-V-V7-I). This harmonic structural pattern became fundamental during the formative years (1939-1963) and continues to be the basic accompaniment that characterizes the stye of popular music in DRC.

The role played by the Greek Basile Papadimitriou, founder of the studio Loningisa in Kinshasa (1950), is summarized by Georges Antippas (2007), when he writes, "Musicalinstruments purchased by Basile Papad-

\footnotetext{
10 See "melorhythm" above.

1 Bob White. Rumba Rules: The Politics of Dance Music in Mobutu's Zaire. Durham: Duke University Press, 2008, p. 32.
} 
África (São Paulo, 1978, Online), São Paulo, n. 42, p. 16-38, 2021

imitriou, were given to the artists." ${ }^{12}$ Luambo Makiadi Franco and founding musicians of the OK Jazz band, for example, are among those who benefited from these gifts. In return, instrument recipients became permanentstudio musicians at the Loningisa studio. This practice was emulated by other recording studios such as the "Olympia", founded in 1939 by the French Patout; "Ngoma", foundedin 1947 by the Greek Nicos Jeronimidis and his brother-in-law Nikiforos Cavvadias. The "Esengo" studio by Constantin (Dinos) Antonopulos was among several other establishedin Kinshasa in the 1950s. The quality of recording sound from "Opika", "Galo", and "Cefa" studios founded by Gabriel and Jose Mussa Benatar (de Rhodes), together with G. Gallotone from South Africa, was characterized by the then rare electric guitar of Bill Aleixandre.

The orchestration of ensembles that perform popular music in the DRC is composed of four chordophones-lead guitar, mi-solo guitar, rhythm guitar, and a bass guitar. This orchestration is derived from the traveling $\mathrm{Cu}_{\text {- }}$ ban ensembles emulated by local musicians during the formative years (19511965). ${ }^{13}$ Each of these instruments participates to the rhythmic structure and harmonic implementation that define the style of the band. In a composition, for example, each instrument provides an accompaniment to the melody performed by a solo voice, singers in unison, or in harmony. The result of this intricate relation of instrumental contributions is a tapestry of both rhythmic parts thatare woven together and move according to the dance rhythm, which is often dominated by an underlying time-line-pattern commonly known throughout Africa. Harmonically, theroot of the chord is played by the bass guitar that also sets the pace for the harmonic progression.

Above the described melodic and rhythmic tapestries resulting from the intricate relations of musical instruments in the band, the lead guitar, with the support of mi-solo guitar, perform interlude melodies in a hocket-technique such as that heard in "Bisalela" by the OK Jazz band. Although the relationship between the lead guitar and mi-solo partsis conceptually like that between time-line-patterns in drum ensemble, practically, their progression is

12 Georges Antippas. Pioniiers Meconnus du Congo Belge. Bruxelles: Inter-Print/Editions Mesoin, 2007, p. 189 .

13 Pioneer Congolese musicians were encouraged by the Greek recording studio owners to emulate the appealing style of Cuban orchestration for commercial reasons. 
KAZADI WA MUKUNA The evolution of harmony in the music of the Democratic Republic of Congo (DRC)

primarily harmonic than rhythmic. Whereas the melorhythm is produced by pitch relationship in a drum ensemble between time-line-patterns, that of melodic formula in a popular music orchestra resides primarily in the pattern of the harmonic progression.

It can then be asserted that in the popular music of the $\mathrm{DRC}$, the melody generatesthe harmony sustained by respective instruments with melodic formula that are also rhythmic. Each formula is recycled (repeated) within the structure of the harmonic progression as dictated by the melody. The resulting relation of this formula serves, firstand foremost, as a harmonic backdrop and secondly as a rhythmic accompaniment determined by the designated dance. Therefore, the quest for the stylistic identity of eachband is of such importance in the popular music of DRC that it became necessary for bands to create a new guitar role between the lead and the rhythm guitars called "mi- solo". In one of my publications, I asserted that the introduction of the mi-solo guitar partin the orchestration of bands, was to accommodate the growing number of unemployed talented musicians who had no bands to play in. To rectify this assertion, I questioned Mr. Lutumba Simaro, the acclaimed mi-solo player in the O.K. Jazz band. Simaro beganhis answer explaining how the guitar player Bill Alexandre introduced the technique of playing guitar with a pick that revolutionized the style of popular music in DRC, Lutumbaconfirms:

Mr. Bill Alexandre, at "Cefa" studio, is the one who came with the style of playing guitar with a pick (mediator), and we adapted that style. It is true that there were too many good guitar players at that time, such as Papa Noel and Leon Bokassa. The latter used this style to accompany his song "Badimwena, mwasi abotamaki na Kini ..." (Badimwena, lady that was bornin Kinshasa). The creation of mi-solo was not because there were severalgood lead guitar players, each period had its own style. ${ }^{14}$

In Congolese bands, the mi-solo plays between the lead guitar player, called in French as soloist, and the rhythm guitar, called accompagnateur. According to composerLutumba Simaro who also played the role of mi-solo in Ok Jazz ensemble for more thanfifty years, "mi-solo provides support to the lead guitar player. In other terms, the role of the mi-solo player is to supplement the lead guitar's part with interlocking formulas that are both melodic

14 Lutumba Simaro interviewed in Linguala May 27, 2010. 
and rhythmic. Often, a melodic phrase or a rhythmic formula is playedin hocket - a device that is expressed in the form of breakdown of a melodic phrase between two instruments. In the present study, segments of the said phrase are playedin a symbiotic relationship between the lead guitar and the mi-solo, with such a perfectionrhythmically and melodically, that the result defies the perception of a casual listener. Only two well-trained and equally sensitive guitar players can make segments of a technically challenging overall formula sound as being played by a single instrument. InAfrican music, Nketia writes.

The hocket is not merely a device but a technique of building up single or parallel linear structures in various types of interlocking patterns. The hockets are not arbitrary artistic devices; they are functional, in the sense that they arise out of melodic and polyphonic considerations. They are oftena means to an end, not an end in themselves, and are used for achieving overall effects of continuity, for building up interlocking, and sometimes complex structures, out of relatively simple elements. ${ }^{15}$

The mi-solo player has, 1) to have a command of his instrument, and 2) to be ableto share enough sensitivity with the lead guitar player, to produce an artistically acceptable musical formula. He must be a virtuoso, in his own right, capable of contributing necessary innovative formula that will interact rhythmically and melodically with those of the lead guitar player. In short, they both must work in dependence with each other. Where this relation is properly carried out, it is challenging for the listeners to distinguish on which instrument and who is the musician, I.e., lead guitar or mi-solo player who has executed the complicated melody.

Examples of the application of the hocket-technique can be heard in the improvisation sections of majority of songs in the popular music of DRC, since the late 1960s. In "Douchaé (Papi Batay)" by Lutumba Simaro and interpreted by the ensemble Bana O.K. ${ }^{16}$ there is a formula that is both melodic and rhythmic divided between two guitars, the lead guitar player and the mi-solo, that requires more than casual attention tocomprehend its musical structure. The musical value and artistic sensibility than are required of the

\footnotetext{
$15 \quad$ Kwabena Nketia, op. cit., p. 52.

16 Simaro Masiya. "Douchae (Papi Batay)” in Proces-Grand Likofi. Paris: Solfege Universel, s/d.
} 
KAZADI WA MUKUNA The evolution of harmony in the music of the Democratic Republic of Congo (DRC)

mi-solo player is heard in the song "Bisalela" also by Lutumba Simaro" and interpreted by the Tout Puissant OKJazz ensemble. The relationship between the lead guitar and the mi-solo in the sebene ${ }^{18}$ section (improvisation section) of this song isboth contrapuntal and hocket in style. Stressing the function and the significance of the hocket-technique in African music, Kwabena Nketia asserts, "Music constructed based on the hocket functions within social situations, and that the significance of the occasionof the performance, the roles of the participants, as well as the activities of the occasion (including the dance) also form part of its meaning." 19

When performing in a dance event, the character of the melody resulting from therelationship between the lead guitar and the mi-solo, reflects the linear flow and the rhythmic basis of the dance. Nketia writes, "A simple tune, a pattern of tone and rhythmresulting from the application of the hocket-technique, may be intended to provide nothingmore than a background for the dance." ${ }^{20}$

The insertion of the dominant-seventh chord in the instrumental harmonic progression, played by the rhythm guitar, increased the element of surprise, and raised the element of tension that requires harmonic resolution-with the return to the tonic (V7-I) of the original tonal center. The novelty and the importance of the dominant-seventh gradually faded out with time, as this role became assigned to the newly introduced instrument in the band-the electronic synthesizer. The dominant-seventh chord in the progression was also the way a player proved his command of the guitar. It was a sign ofan accomplishment for the guitar players in the band who began to refer proudly to the added seventh note of the chord simply as "seven". The meaning of the latter word raisesunanswered questions and confusion to students of this music

17 Simaro Massiya Lutumba. 40 ans de cariere musical: Legende Collection Versions Originales vol. 2, (s/d) NGOYARTO 0102.

18 Sebene is a musical section in the imrovisation section during which musical instruments are engaged in a rhythmically tight and well-balanced rapport with each other. This same term is employed by the younger generation musicians tp refer to the role of mi-solo in a band. Simaro Lutumba explains," when the young people arrived with their mi-solo, they simply began to call it Sebene, thus one would hear, "that little boy plays a great sebene" (l'heure ba petit baye, na ba mi-solo na bango ba bandi kobenga yango kaka Sebene:

"Petit, wana abeta sebene danger)

19 Kwabena Nketia, op. cit., p. 52

20 Idem. 
genre, as to its associationwith the expression sebene that is often used to refer to an instrumental passage of the composition in which all instruments have attained/riched a tight rhythmic, harmonic, volume, and timbre, balance. Etymologically, "is the word sebene a mispronunciation ofthe English-seven?" In addition, according to Lutumba Simaro, now, the younger generation musicians also use this term to refer to the role of the mi-solo: "When the young generation of musicians called their mi-solo, sebene. For example, you will hear them saying, "that little boy plays an excellent sebene." You will hear the proof of what I am saying in the song "Dati Petrole". ${ }^{21}$

To the musician such as Kalala Jean "Goubald" who has a wide range of playing exposure with bands from different traditions outside of Africa, that included but were notlimited to Europe and Turkey ensembles, the diatonic harmonic progression is very restrictive. In a conversation with Jean "Goubald" on this subject in a club located in thetownship of Lemba, and at my research residence in Kitambo (DRC), he lamented this harmonic strait jacket practice in the popular music of DRC. ${ }^{22}$ "Our vocalists as well as our musician minds," he states, "are accustomed to the sound of foreign harmony in their musical vocabulary. To demonstrate his point, Jean Goubald incorporates an orchestration strongly influenced by the musical style from these foreign countries in his song "Emi Souvient Toi" (Emi, Remember).23

\section{Vocal Harmony}

Unlike the evolution of the harmonic texture of popular music in DRC, which is founded on similar interactive organizational principles as those of traditional drum ensembles, the texture of vocal harmony is governed by the semantic requirements of tonal languages in Africa. ${ }^{24}$ The overall texture of

\footnotetext{
21 Interview with Lutumba Somaro in Kinshasa, May 27, 2009.

22 My interview with Jean Goubald in Super Lemba, June 2009 and Kitambo, July 2009, townships of Kinshasa, DRC.

23 "Emi Souvient Toi" in the album Bombe Anatomique contains songs with chord progressions andcharacter conducive to those of other cultures.

24 See Kazadi wa Mukuna. "Creative Practice in African Music: New Perspectives in the Scrutiny of Africanisms in Diaspora." Black Music Research Journal. 17 (2), pp. 239-250,
} 
KAZADI WA MUKUNA The evolution of harmony in the music of the Democratic Republic of Congo (DRC)

vocal harmony is also tinted by the sound of foreign bands heard on the radio broadcasts and in concert halls, during their tours. ${ }^{25}$ In each of these scenarios, Congolese musicians reinforced the adapted diatonicharmony that characterized the style of their popular music since its inception. The resulting harmonic texture is a hybrid product different from the performance-compositionof the traditional percussive ensemble.

In Paul Collaer's article discussed above, he failed to consider the fundamental causality of the predominance of parallel singing in Africa. The language plays a vital rolein the vocal music of Africa. The semantic level of the language provides the melodic contour, the harmony, and the rhythmic aspects of the song. In Africa, most languages are tonal, i.e., the meaning of the word is determined by the sequential pattern of its tones, which also constitutes the semantic level of a word. Any variation/modification of a tonechanges the meaning of that word. As such, then, in the vocal music pf Africa where thebasic melodic contour of a melody is provided by the high-and-low pattern of tones of lyrics. For example, in Lingala language the meaning of the word mabele does not carryany meaning until the tones have been placed. Màbélè means milk or breast, and màbèlé means dirt (ground). The meaning of these two words does not change, regardless of any syntactic position they occupy in a phrase. Therefore, to maintain the meaning of a word, the composer is compelled to respect tonal patterns in the text. Therefore, in the vocal music of Africa, the default harmonic texture is parallel. It should be pointed out here that parallel singing is not the only genre of harmonic implication in Africa. In communal singing where songs are harmonized by individuals, it is not unusualto hear voices performing syllables in a staggered fashion. This practice produces the heterophonic harmony, which is also linguistically derived and unique to every linguistic group.

Often, this discussion is totally avoided in published documents about the urban music of DRC. For example, in his classic text Terre de la Chanson: La Musique ZaïroiseHier et Aujourd'hui, the Congolese writer Manda Tchebwa ${ }^{26}$ avoids this topic all together,while in Rumba Rules: The Politics of

25 Kazadi wa Mukuna. "Ethnomusicology and the Study of Africanisms in the Music of Latin America: Brazil," in Turn up the Volume: A Celebration of African Music edited by Jacqueline Cogdell DjeDje. Hong Kong: South Sea International Press, 1999, pp. 182-185.

26 Manda Tchebwa. Terre de la Chanson: La Musique Zairoise Hier et Aujourd'hui. Brussels: Duculot 
Dance Music in Mobutu's Zairre, the Canadian anthropologist Bob W. White ${ }^{27}$ perfunctorily mentions harmony in the chapter "The ZairianSound", and suggests that the existence of a difference between the two stylistic schools ${ }^{28}$ in the Musique Moderne Congolaise, without revealing specifically their characteristic criteria, or their distinguishing stylistic treatment of musical elements. Commenting on the use of parallel harmony in the urban music of DRC, in the same chapter, White writes, "Another important aspect of the sound is the use of parallel vocalharmonies. Singers, usually between three to five in number, will sing harmonies that begin at fixed intervals (thirds, fourths, fifths) up or down from the notes of the primary melody." ${ }^{29}$

In the chapter devoted to "Musicians and Mobility", White returns to the topic of vocal harmony with a different, outsider point of view about the existence of what he callsa "complex harmonic and rhythmic combinations in vocal lines" ${ }^{30}$ This statement and similar others relative to the nature and the organization of African music (traditional and urban), ${ }^{31}$ reflects the cultural foundation of their authors. This point of view is grounded in cultural misunderstandings of, or they simply reveal the failure of their authors to assessthe popular musical expression of DRC within its own cultural context. Despite the enormous amount of literature devoted to the explanation of the nature of this music, ${ }^{32}$ the nature and the governing principles of its organization continue to challenge the scrutiny of casual scholars and to evade the attention of seasoned researchers, despite of their noble intention. Often, these researchers prefer to simplify the argument about the organizing norms of African music by casting or assessing them outside their culturalcontext, and/or they refuse to

Afrique Editions, 1996.

27 Bob W. White. Rumba Rules: The Politics of Dance Music in Mobutu's Zaire. Durham: Duke UniversityPress, 2008.

28 African Jazz and O.K. Jazz styles.

29 Bob White, op. cit., p. 32.

30 Ibid., p. 134.

31 The misunderstanding of the organization of rhythm (instrumental and vocal) in African music expressed in the documents, is written by early European travelers who believed that music diid not exist outside of Europe.

32 Articles written by Congolese writers abound on various aspects of this music. 
KAZADI WA MUKUNA The evolution of harmony in the music of the Democratic Republic of Congo (DRC)

accept that the creative process of African music, in general,is governed by a set of principles different from those of Europe.

In the present article, I have provided the reader musical evidence (transcriptions)tracing the evolution of vocal harmony, and the explanation for their causality. I have alsopointed out that this causality is rooted within the linguistic realm. This harmonic implication in vocal music is not as complex as Bob White suggests. On the contrary, it isthe by-product of the "semantic level" of lyrics expressed in Lingala - the vernacular language. Thus, the same linguistic ground rules can also be applied to any tonal language spoken in Africa. In the detribalized city of Kinshasa, for example, lyrics are modified and adapted to a series of social, economic, religious, and political, factors that

are unique to this city. As the lingua franca of the country, Lingala incapsulates all characteristics of expression and the source of inspiration for the composition of melodiccontours, the harmonic implication, and rhythmic structure. This determining factor of theLingala on the popular music of the $\mathrm{DRC}$, for example, is detectable in the daily friendly verbal exchanges. It is not uncommon to hear a mixture of languages, French, Kikongo, Tshiluba, Swahili, and even English in a single conversation. It can then be asserted that in Kinshasa, only an expatriate communicates in one single language. White failed to understand this multilanguage communication skill by the Kinois, ${ }^{33}$ when he writes,

La musique moderne is sung primarily in Lingala, a local African language that for historical reasons stands as an icon of a cosmopolitan urban identity. In the rare cases in which Lingala is not used for the primary lyrics of the songs, it is usually substituted with languages considered morecosmopolitan such as English, French, or Spanish..$^{34}$

I declare that the use of foreign words in lyrics of popular songs in the Democratic Republic of the Congo fulfils linguistic and musical roles. Firstly, Lingala is a standard conversational language in Kinshasa. Secondly, in music, this practicedemonstrates that in the compositional process, the signification of melodic linessupersedes that of lyrics. Ndombe Pepe explains,

33 Name utilized to refer to citizens of Kinshasa.

34 Bob W. White, p. 32. 
When one has a melody in mind, you can attribute it a word; you can say that word in any language. That melody will continue to exist. It is not necessarily true that if you translate that word into another language, that melody will not come. That is not so, because the melody comes after. ${ }^{35}$

In other words, where a word or a combination of words, with specific sequential tonal patterns in Lingala cannot fit into the desired melodic contour without forcing the composer to rewrite the melody, a word in a foreign language, with similar meaning in thephrase and the storyline, same meaning, is substituted to maintain the melodic contour. In some circumstances, the borrowed word in foreign language is Lingalized.

Elsewhere, ${ }^{36} \mathrm{I}$ assert that in Africa, languages play a vital role in determining the nature of the music, its rhythmic organization, and harmonic implication. In the same source, I also assert that in the vocal music, the semantic level of the language (tonal sequence of each word) dictates the direction of the musical interval, but not its size. In the popular music of DRC, the melodic contour is derived from the song lyrics. This practice corroborates Ndombe Pepe's statement above that the lyrics come first and thenthe melody. The popular music of the DRC abides by this ground rule and answers the question as to which aspect is composed first - the lyrics or the melody.

The English expression "he died", for example, can be lingalized as "a daya"; andthe French verb "addresser" is lingalized as "sadressaka". To comprehend the concept of this linguistic practice, first, understand the description discussion above, to view the impact of the linguistic mechanism in the development of popular music of DRC.

This technique of substituting words in foreign language, especially English, French, and Spanish in the lyrics of the popular music of the Democratic Republic of theCongo has often attracted scholars' attention as they seek to decipher their impact in the compositional technique. Scholars would like to know the way in which the mixture of languages in the compositional process of melodic patterns of songs in Lingala. The explanation given by vocalist Ndombe Pepe, who composed some of the most popular songs, such as

\footnotetext{
35 Interview with Ndombe Pepe in Matonge, June 3, 2009

36 Kazadi wa Mukuna. "Creative Practice in African Music: New Perspectives in the Scrutiny of Africanismsin Diaspora.” Black Music Research Journal 17, 2 (FALL 1997): 239-250.
} 
KAZADI WA MUKUNA The evolution of harmony in the music of the Democratic Republic of Congo (DRC)

“Esakola ya Mawa, M.C.”, interpreted by the Bana OK band in 2001, sheds light on this preoccupation:

Solo: Esakola ya mawa nakomi nde na suka Sad announcement, I have reached the bottom

Nakomi dessu, motema epayi na mipesaki esimbi te

I've been deceived, where I gave myself, it didn't work

Naye komikotisa na monyololo

I've placed myself in jail

Chorus: Soufrance

Miseries

Solo: Nzoto na ngai nzoto ya molende

I have a strong body

Chorus: Fragile

Fragile

Solo: Nalobaka te mabe monoko bapesa ngai

I do not speak with this ivel month tha I was given

Chorus: Silence

Quiet

Solo: Maloba na ngai kaka ya l'amour

My words are just about love

Chorus: Esadresaka kaka na yo, jour et nuit

They are always addressed only to you

It is within this frame of reference that the vocal harmony in la musique moderne in DRC has evolved, bound by the same linguistic guidelines that dictate the direction of the intervals in a melodic phrase of traditional music. These constructive principles are also encountered at the base of the heterophony - a harmonic texture obtained whenever versions of the same melody are performed simultaneously. It is then safe to assert that until recently, the topic of harmony in the popular music of DRC was avoided by scholars because of the inability to misunderstanding subtle causality of their evolution. While I have nothing against outsiders attempting to write about the popular music of DRC, I want to make them aware of the bundle of deep-seated cultural information about this music that is deciphered best by insiders. The investigation of any genre of music in Africa, must initiate, first and foremost, with the identification of the language where it derived the nature of all elements. In the popular music of DRC, one must proceed beyond his/her 
África (São Paulo, 1978, Online), São Paulo, n. 42, p. 16-38, 2021

mere ability to speak Lingala, and delve into the overall culture of Kinshasa, which impacts the behavior that produces the popular music and the lyrics. Articles dealing with this truth abound. I have repeatedly demonstrated and sustained this assertion in several articles previously published in journals and as book chapters.

The following transcriptions are songs interpreted by the OK Jazz ensemble between 1956 and 2009, ${ }^{37}$ to illustrate that the vocal harmony is a mixture of textures ranging from the duet to multi-voices parallel singing [see Figure 1 - "Yuna"]. In some songs, the alternation is caused by the combination of natural vocal ranges of singers. The examination of these harmonic textures reveals clear evidence of how the requisitesof linguistic tones in African languages have been rigorously applied even to words fromsuch atonal language as French, heard in "Esakola ya mawa MC".

During the period following the so-called the "Brass tradition" of the urban music inDRC, the impact of Latin American was prominent in music, dance, clothing, and even names of musician. ${ }^{38}$ As musicians were learning a new musical expression, songs in Lingala were often spoken with words in Spanish language to emulate the models from Cuba and the Dominican Republic. Singer composer Lando Rosignol who was famous for his interpretation of songs in cha-cha-cha rhythm, also composed songs in Lingala laden with Spanish words. In Kinshasa, Cuban musical forms were dominant, musicianscomposed songs in which a single idea was developed without commentary. These shortsongs mostly in cha-cha-cha, became characteristic of the period for their intersected Spanish words and for not expressing a coherent message.

When asked about the meaning of what he was singing in Spanish, Lwambo Makiadi Franco, who was also prolific in bolero, answered, "in those days we used dictionary and picked up words that sounded good and

\footnotetext{
37 Troubadour era (1935-1953); Formative Years (1953-1963); Development Period (1963-1973); YoungGeneration Era (1974-1984); The Era of Ndombolo (1984-1997); The Era of Ngwasuma (19972005); The Era of Malewa (2006-2012); The Vimba period (2012-20180; System ya Benda (2019-present).

38 See Kazadi wa Mukuna. "The Evolution of Urban Music during the $2^{\text {nd }}$ and $3^{\text {rd }}$ Decades (19751985) ofthe Second Republic - Zaire.” Journal of African Music 7 (4) 1999, pp. 73-87.
} 
KAZADI WA MUKUNA The evolution of harmony in the music of the Democratic Republic of Congo (DRC)

composed the entire song aroundthose words". ${ }^{39}$ "Cha-cha-cha, Umbadi kento de mi amor, cha-cha-cha", for example, constituted a refrain of one of the most popular songs of the period for which the one wordverse was repeated "baila, baila, baila". ${ }^{40}$

Several bands specialized their repertoire to only one genre (form). The prominentband like O.K. Jazz under the leadership of singer, composer, lead-guitar player LwamboMakiadi Franco, released a series of compositions in cha-cha-cha form with Spanish titles: Such songs as "Cha-cha-cha de mi amor [Cha-cha-cha my Love] by Brazos, and Es mi Cumpleaños (It is my Birthday) by the leader of the band Franco", ${ }^{41}$ are samples ofthe linguistic mixture. The pioneer vocalist and leader of the first Congolese band AfricanJazz (1953) modeled instrumentally after the Cuban combo, Kabasele Tshamala also known as Grand Kallé, devoted his entire career singing mostly Latin styled songs with his original band and or as a guest artist with Cuban ensembles (Homage a Grand Kallé). Despite the success of these giants of Congolese popular music, none could excel the "Rock-a-Mambo" band under the leadership of the tenor vocalist Lando Rosignol in the interpretation of cha-cha-cha.

Spanish remained the preferred language for Bolero and Cha-cha-cha songs through the first half of the 1960 as the interpretation of this and other Cuban dance rhythms were being mastered on imported musical instruments such as guitar, up-right acoustic double bass, the conga, the maracas, and the clave, by local bands. ${ }^{42}$ Writing on this issue Sylvain Bemba summarizes the popularity of Spanish language and cha- cha-cha in these terms:

Introduced in Spanish packaging, the cha-cha-cha is enthusiastically adopted by "Congolese" musicians jabbering the language of Cervantes sowrong that they create a babir (lingo) called Hindoubil. It's a kind of invertedLingala, mixed with Spanish expressions. Middle language, an environment where one bathes in the vapors of hemp, the rumor affirming that the musicians can only

39 Interview with Franco in Washington, DC., June 13, 1988.

$40 \quad$ Idem.

41 Manda Tchebwa, op. cit., p. 65.

42 See Kazadi, Pierre. "The Origin of Zairean Modern Music: A Socio-Economic Aspect.” African UrbanStudies: Readings in African Urban Music 6 (Winter 1979-80): 31-39. 
África (São Paulo, 1978, Online), São Paulo, n. 42, p. 16-38, 2021

give their full potential under the doubling and stimulating influence of the djamba (marijuana). ${ }^{43}$

Bolero and Cha-cha-cha songs of this period had a certain characteristic and flairlike those of $\mathrm{Cuba}$ and they were interpreted accordingly by lead tenor voice and a harmonized refrain sung by a duet or a trio of male voices. The Spanish words which were primarily for effect had a very little impact on the song. It can be concluded with impunity that contrary to the compositional technique of songs in African language in which the direction of the interval is dictated by the sequential pattern of its tones, or thesemantic level of the language, the text was secondary. The melody was conceived first, and the lyrics added to it. In other words, in this case, the melody was more important than the words and as such, the musical character of these songs was independent of tonal influence.

The mixture of foreign languages, especially French in the popular music of the Democratic Republic of the Congo has played a vital role in the compositional procedureespecially in songs composed in Lingala, the lingua franca of the country. Elsewhere, ${ }^{44} \mathrm{I}$ assert that in Africa, language plays a vital role in determining the nature of the music, the musical style of an ethnic group, particularly its heterophonic singing. Language is also the determining factor in the selection of a musical instrument with which an ethnic group will be identified, based on the ability of the instrument to reproduce the linguistic tones of the ethnic group in question. It is not a coincidence that many ethnic groups utilize a two-tone musical instrument for communication practice, since the semantic aspect of their languages is composed primarily of two tones high and low or rise and fall. In the semantic realm of the Yoruba language in Nigeria, for example, which has more than high/low tones, a different musical instrument - Dùndún - is selected as the talking drum because of its capability to reproduce the variety of tones in the language and their combinations.

Having lost the semantic level of their languages in the New World, African slaveslearned the semantic of the languages of their masters, but they

43 Bemba, Sylvain. Cinquante ans de musique du Congo-Zaïre, 1920-1970: de Paul Kamba à Tabu-Ley. Paris: Présence Africaine, c1984, p. 108.

44 Kazadi wa Mukuna. "Creative Practice in African Music: New Perspectives in the Scrutiny of Africanismsin Diaspora.” Black Music Research Journal 17, 2 (FALL 1997): 239-250. 
KAZADI WA MUKUNA The evolution of harmony in the music of the Democratic Republic of Congo (DRC)

expressed the semanticaccording to the syntax of their African languages of origin. In the same source, I arguedthat African languages being tonal, any modification to the sequential patterns of tones on each word brought change to the meaning of the word. Therefore, to maintain the meaning of each word, in a song, the semantic components of the language must be observed. In practice, this aspect of the language dictates the direction of the interval while leaving their sizes to the artistic discretion of the composer.

Although the popular music of the Democratic Republic of Congo (DRC) abides by this ground rule, a question such as "which aspect of the song is composed first - the lyrics or the melody?", comes to mind whenever this issue is entertained. In this article, I am arguing that in recent compositions, both aspects are observed, giving rise to two types of melodic structures, derived from the content of lyrics of the song. Frequent insertions of French words into Lingala songs brought a different quality in the popular music in the Democratic Republic of Congo. In this case, although the lyrics are primarily in Lingala, the insertion of French words provides a smooth transition in the structure of the melodic contour. As musicians took residence in Europe, their compositional techniques were also affected, especially in the attempt to have their songs understood by their new clients, songs were now being composed with a significant number of French words or simply in French. When considering the rhythm for the dance, the instrumentation, and the harmony, these songs have changed their character considerably.

In the song "Kenge okeyi elaka te?" by Franco and interpreted by the OK Jazz during the formative years (1953-1960), for example, vocalists Vicky Longomba and EdoNganga harmonize each other in the refrain section in the dominant style of the period, parallel thirds. Their vocal harmony was echoed by Musekiwa Isaac on the clarinet and Franco on the lead guitar [see Figure 2 - "Kenge okeyi elaka te?"]. Parallel harmonization with several voices is also common in responsorial songs [See Figure 3- "Male"] by Pepe Ndombe, interpreted by Bana O.K..

In summation, in this article I have demonstrated three genres of harmonic implication in the popular music of $\mathrm{DRC}$, setting the stage with: 1) The linear harmony of the Ensemble Thematic Cycle of traditional drum ensembles, 2) The European influencedchord progression performed on a variety of Western musical instruments, thus providinga tapestry of instrumental 
África (São Paulo, 1978, Online), São Paulo, n. 42, p. 16-38, 2021

sounds on which the lead-guitar and the mi-solo guitar playersimprovise, and 3) pointed out that the causality of parallel harmonization in the vocal music of Africa is the tonal constraints or semantic level of the language, which is felt in structure of melodic line.

\section{REFERENCES}

Antippas, Georges. Pionniers Méconnus du Congo Belge. Bruxelles : Inter-Print/Éditions Mesoin, 2007.

Bemba Sylvain. Cinquante ans de musique du Congo-Zaïre, 1920-1970: de PaulKamba à Tabu-Ley. Paris: Présence Africaine, c1984.

Collaer, Paul. “Notes sur la Musique d'Afrique Centrale." Problèmes d'Afrique Centrale 26 (1954), p. 269.

Dawe, Kevin. The New Guitars cape in Critical Theory, Cultural Practice and MusicalPerformance. Burlington: Ashgate Popular and Folk Music Series, 2010.

"Harmony." In The Oxford Dictionary of Music, $2^{\text {nd }}$ ed. Rev., edited by Michael Kennedy.

Oxford Music Online. http//www.oxfordmusiconline.com/subscriber/article/opr/t237/e4724 - AccessedDecember 15, 2010.

Kazadi wa Mukuna. "Congo, Democratic Republic of: Modern and Contemporary Performance Practice," in SAGE Encyclopedia of Popular Music. ThousandOaks: SAGE Publications, 2019, pp. 640-643.

. "The Evolution of Popular Music in the Third Republic of the Democratic Republic of Congo [1997-2018] - Years of Artistic Sterility." RevistaClaves - Dossiê "Matizes Africanos na Música Brasileira" Vol. 9, número 14, 2020.2, pp.32-42.

. "Africanisms in the Afro -Brazilian Musical Cultures: A Linguistic Consideration," in La Música entre Africa y America, edited by Coriún Aharonián.Centro Nacional de Documentacion Musical Lauro Ayestarán. Montevideo (Uruguay), 2013, pp. 121-129.

"Resilience of African Musical Elements and the Effect of Linguistic Syntax on Rhythmic Organization in Diaspora," in 200 Years Later: Commemorating the 200 Year Anniversary of the Abolition of the TransatlanticSlave Trade edited by Nadja Ofuatey-Rahal. Berlin: Werkstatt der Kulturen, 2008, pp. 89-94.

"The Origin of Zairean Modern Music: A Socio-Economic Aspect."African Urban Studies: Readings in African Urban Music 6 (Winter 1979-80): 31-39. . 'The Evolution of Urban Music during the $2^{\text {nd }}$ and $3^{\text {rd }}$ Decades(1975- 
KAZADI WA MUKUNA The evolution of harmony in the music of the Democratic Republic of Congo (DRC)

1985) of the Second Republic - Zaire." Journal of African Music 7 (4) 1999, pp. 73-87.

. "Creative Practice in African Music: New Perspectives in the Scrutiny of Africanisms in Diaspora." Black Music Research Journal 17, 2 (FALL1997): 239-250.

. "The Changing Role of the Guitar in the Urban Music of Zaire." The World of Music 36 (2 1994, pp. 62-72.

"Evolution de la musique urbaine au Zaire Durant les dix premières années de la Deuxième République (1965-1975).” L'Aquarium 11/12(Printemps), 1993, pp. 65-71.

(2) 1992 , pp. $72-84$.

"The Genesis of Urban Music in Zaire." Journal of African Music 7

Manda Tchebwa. Terre de la Chanson: La Musique Zairoise Hier et Aujourd'hui. Brussels: Duculot Afrique Editions, 1996.

Mark Spicer, Mark and John Covach, eds. Sounding out Pop: Analytical Essays inPopular Music. Ann Arbor: University of Michigan Press, 2010.

Nettl, Bruno. Nettl's Elephant: On the History of Ethnomusicology. Chicago: Universityof Illinois Press, 2010.

Nketia, J. H. Nkwabena. "Developing Contemporary Idioms out of Traditional Music," in Ethnomusicology and African Music: Modes of Inquiry and Interpretation - Collected Papers, Volume one. Accra: Afram Publications (Ghana) Ltd, 2005, pp. 337-364

Folk Music Council Vol. 14, 1962, pp. 44-52.

"The Hocket-Technique in African Music." Journal of theInternational

Nzewi, Meki. African Music: Theoretical Content and Creative Continuum - The CultureExponent's Definitions. Olderhausen, Germany: Institut für Didaktik Populärer Musik, 1997.

Spicer, Mark and John Covach, eds. Sounding out pop: analytical essays in popularmusic. Ann Arbor: University of Michigan Press, 2010.

Tenzer, Michael, Ed. Analytical Studies in World Music. Oxford: Oxford UniversityPress, 2006.

White, Bob W. Rumba Rules: The Politics of Dance Music in Mobutu's Zaire. Durham: Duke University Press, 2008.

https://search.yahoo.com/yhs/search?hspart=trp\&hsimp=yhs- $\quad 001$ \&grd $=1$ \&type $=$ Y61 F1_148993_042821\&p=cultural+relativism +definition\&rdr=1 - Accessed September 17, $20 \overline{2} 1$. 
África (São Paulo, 1978, Online), São Paulo, n. 42, p. 16-38, 2021

\section{Yuna}

Composed by Lutumba Simaro "Poete"

Interpreted by "Bana $O K^{\prime}$
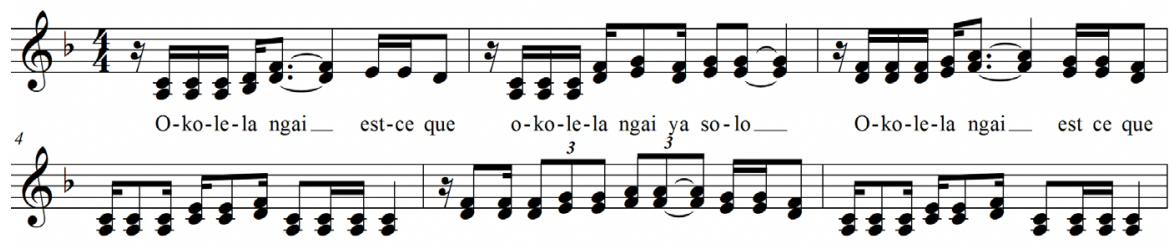

o-ko-bi-mi-sa ma-yi na mi-so. Mo-ko-lo na ko-ku-fa__est-ce que o-ko-la-te-la ngai mo-ku-ya.
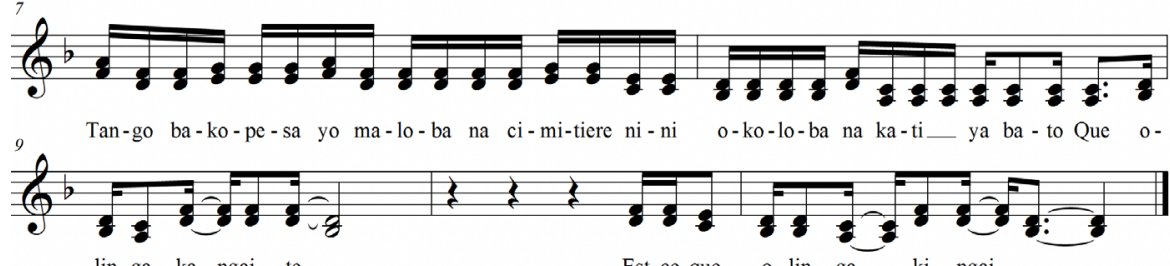

lin-ga - ka ngai te._-

Est-ce que

o- lin - ga - ki ngai.

Figure 1 - Yuna

Kenge Okeyi Elaka Te

Composed by Lwambo Makiadi "Franco"

Interpreted by $O K . J a z z$
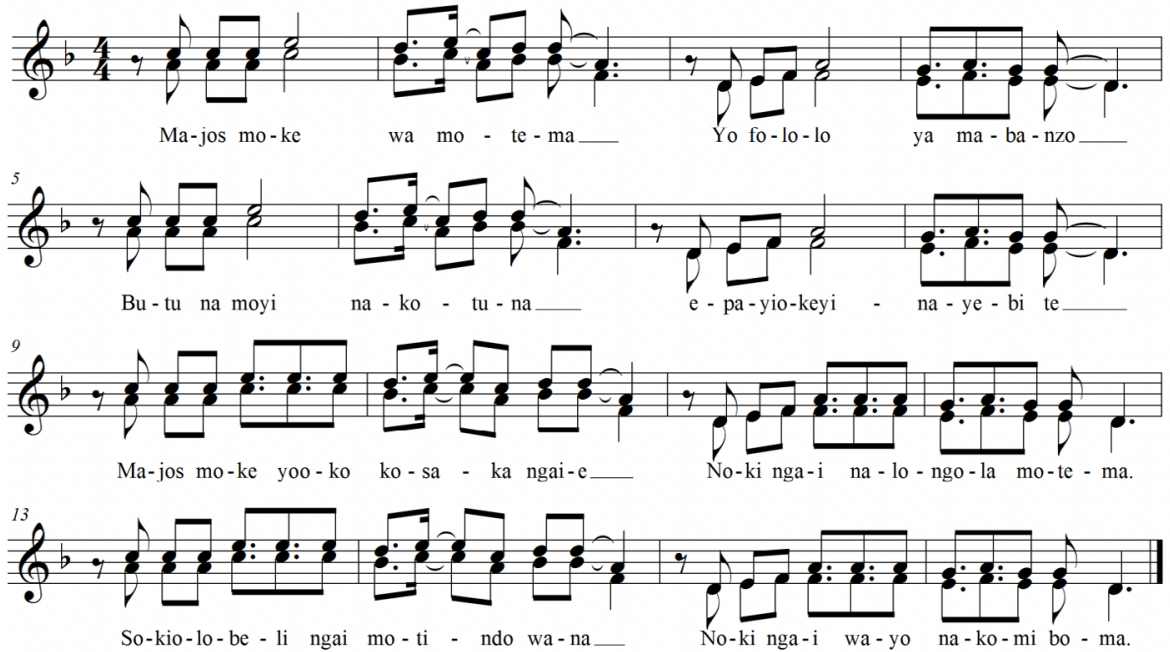

Figure 2 - "Kenge okeyi elaka te ?" 
KAZADI WA MUKUNA The evolution of harmony in the music of the Democratic Republic of Congo (DRC)

Male

Composed by Ndombe Opetum "Pepe"

Interpreted by Bana OK Jazz
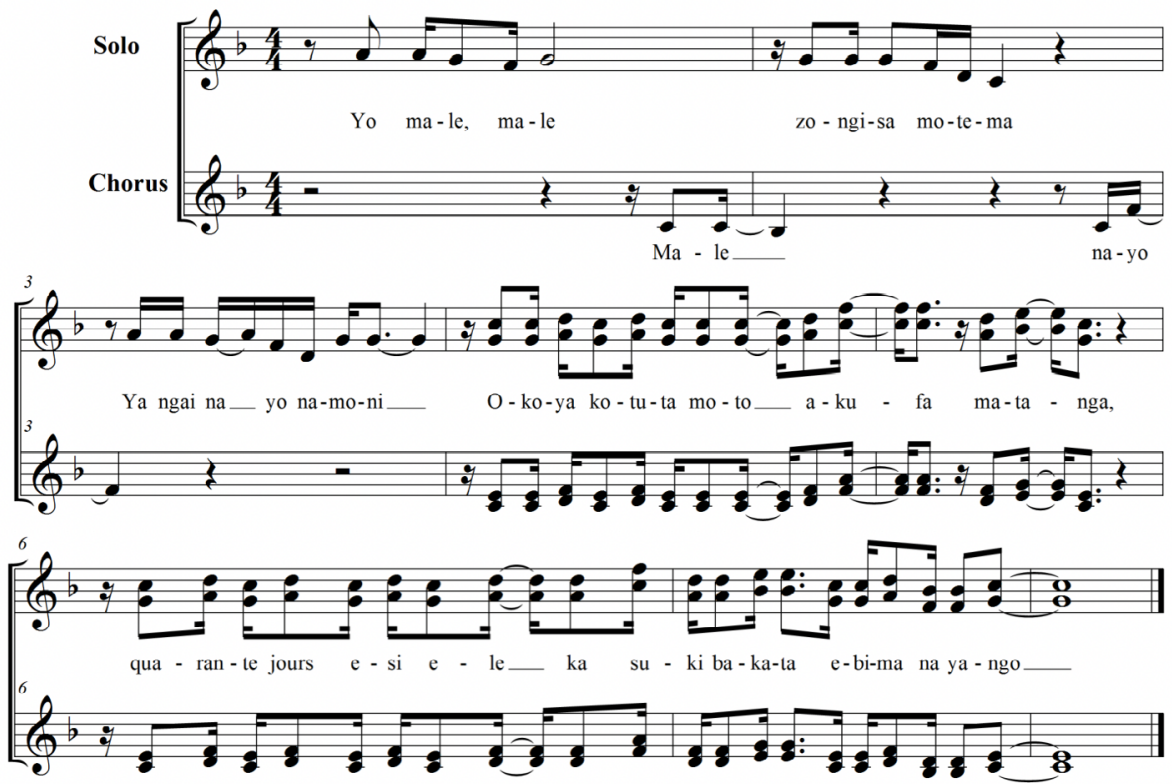

Figure 3 - "Male" 